\title{
New Evidences which Support Existence of the Forced Heat Exchange Phenomenon
}

\author{
Nikolai I. Kobasko
}

\section{ABSTRACT}

In the paper the forced heat exchange phenomenon is validated based on experimental data shown by different authors in different countries and published in respected scientific journals. Software IQLab and regular thermal condition theory were used for solving inverse problems. The data of silver and copper spherical probes quenching in electrolytes were used. As in previous publication, it was established in the paper that heat transfer coefficients (HTCs) increase versus time during quenching of silver and copper probes in electrolytes. As noted early, all of this contradicts the theory of transient nucleate boiling processes. The problem is solved by periodical replacement of film boiling by shock boiling with the high frequency that takes place during quenching. The new idea can be used in practice for designing new and original quenching technology to save materials, increase service life of machine components and also provide an environmentally friendly solution. The importance of new technologies is widely discussed in the paper.

Keywords: New phenomenon, additional evidences, shock and film boiling replacement, advanced technology.

\author{
Published Online: January 16, 2021 \\ ISSN: $2684-4451$ \\ DOI : 10.24018/ejphysics.2021.3.1.41 \\ Nikolai I. Kobasko * \\ $\mathrm{PhD}$, Fellow of ASM International, \\ Intensive Technologies Ltd, Kyiv, \\ Ukraine. \\ (e-mail: nkobasko@gmail.com)
}

*Corresponding Author

\section{INTRODUCTION}

A new phenomenon of physics was discovered recently which consists in periodical replacement of film boiling by shock boiling with the high frequency [1], [2]. The idea was formulated after analysis heat transfer coefficients (HTCs) connected with the quenching of silver probe in electrolytes of optimal concentration. As known, the density of free electrons in silver probe is much higher as compared with steel. When quenching the silver probe in electrolyte of optimal concentration, the double electrical layer is immediately formed where high electrical forces appear. These electrical forces move the film boiling boundary to metal resulting in shock boiling process. On the other hand, silver, due to its very high thermal conductivity, generates very high heat flux density resulting in film boiling process. Balance between them can be created when periodical process starts. Such periodical process easily explains the contradiction consisting in increase the heat transfer coefficient (HTC) versus time during quenching because the role of film boiling decreases and nucleate boiling increases. The discussed idea was supported by data obtained during quenching of silver probe. To be sure that idea works, in this paper additional experimental data were used for solving direct and inverse problem to see similar results during quenching of copper probe. Also, elevated temperature of electrolyte should decrease average heat transfer coefficients (HTCs) during quenching of silver or copper probes if the mentioned phenomenon exists. Proceeding from this point, the experimental results of French and Petrash [3]-[5] were used for evaluating HTCs and after appropriating their analysis is clearly seen that discovered phenomenon can be used for developing new technologies. These important problems are discussed below.

\section{ANALYSIS OF FRENCH's EXPERIMENTS}

There are many published accurate experiments of French [3], [4] which can be used for solving inverse problem and analyzing results of calculation to support the idea on existence of forced heat exchange phenomenon. In the paper were used experiments of French made with steel and copper spherical samples 1.5 inches $(38.1 \mathrm{~mm})$ in diameter. The thermocouples were located on the surface of spherical samples and in their centers. Some results of his accurate experiments are presented in Fig. 1.

As is seen from Fig. 1, during quenching of steel sample the self - regulated thermal process is established immediately after immersion the sample into liquid. To restore the surface temperature up to end of transient nucleate boiling process, the equation (1) was used [2]:

$$
\tau_{n b}=\bar{\Omega} k_{F} \frac{D^{2}}{a}
$$

For still bath the convective HTC is approximately equal to $1000 \mathrm{~W} / \mathrm{m}^{2} \mathrm{~K}$ while for agitated bath with $1 \mathrm{~m} / \mathrm{s}$ it is equal to $4000 \mathrm{~W} / \mathrm{m}^{2} \mathrm{~K}$. For both conditions the convective Biot numbers are: $\mathrm{Bi}=0.83$ and $\mathrm{Bi}=3.3$. According to Ref. [2], for given convective Biot numbers $\bar{\Omega}=3.5$ and $\bar{\Omega}=2$. 
For the first and second cooling conditions the duration of the self - regulated thermal process is $\tau_{n b}=3 . .5 \times 0.0253 \times \frac{(0.038 .1)^{2}}{5.4 \times 10^{-6}}=23.8 s$ and $13.6 \mathrm{~s}$.

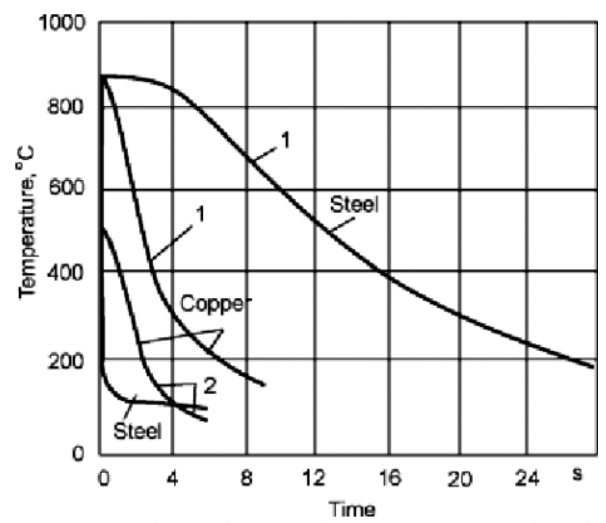

Fig.1. Temperature at the surface and in the core versus time for steel and copper spherical samples of $38.1-\mathrm{mm}$ diameter, quenched from $875{ }^{\circ} \mathrm{C}$ in water at room temperature (French's experiment [3]): 1, core; 2, surface.

Using reconstructed surface temperature of French, the core temperature curve was calculated to compare it with the experiment of French (see Fig. 2). Results of experiment and calculations coincide well enough. It means that we can expect correct dada in heat flux density and HTC calculations. The calculations were fulfilled using thermal properties which are presented in Table 1 and Table 2 .

Fig. 2 shows the reconstructed surface temperature which was used for heat flux density and heat transfer coefficients calculations presented in Fig. 3 and Fig. 4.

By comparing core cooling curves on Fig.1 and Fig. 2, it is seen that calculated and experimental data coincide very well enough. The small difference between them is explained by some differences between thermal properties of materials and grain sizes of microstructure of steel which was tested.

As seen from Fig. 3, the maximum heat flux density appears at the very beginning of quenching that is explained by shock boiling process. It lasts approximately one second and heat flux density during this time drops to $3 \mathrm{MW} / \mathrm{m}^{2}$. This is worth to know when developing new quenching technology based on use external electrical forces.

The same trend in decreasing the heat transfer coefficient versus time is shown in Fig. 4. During quenching of steel spherical probe, the heat transfer coefficient decreases exponentially very rapidly beginning from the shock boiling process (see Fig. 4).

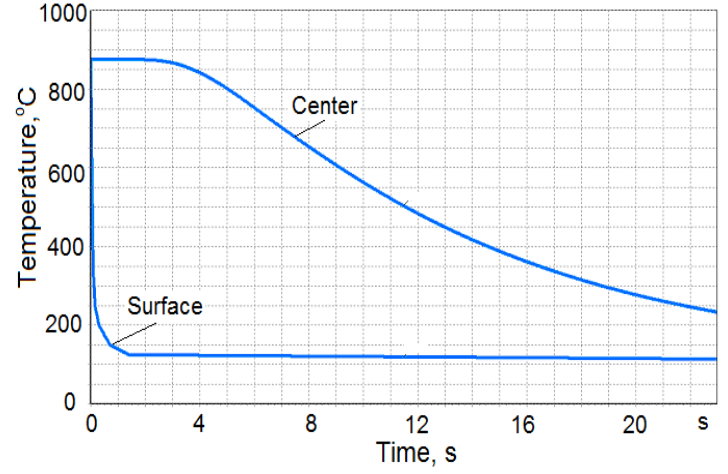

Fig. 2. Surface and core temperature cooling curves versus time during quenching from $875^{\circ} \mathrm{C}$ spherical probe $38.1 \mathrm{~mm}$ diameter in low concentration of electrolyte at $20^{\circ} \mathrm{C}$.

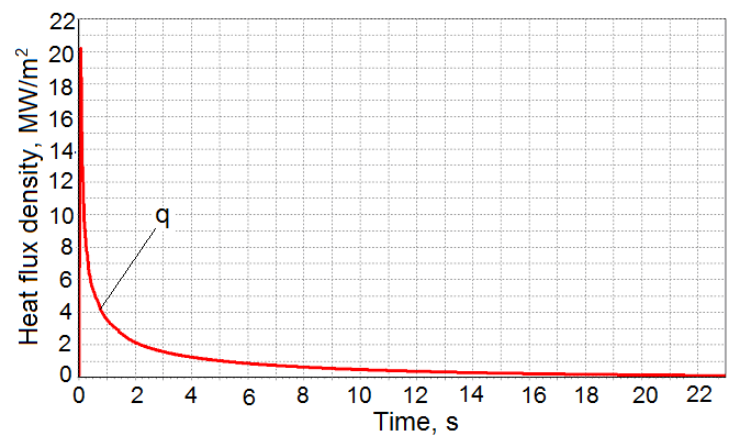

Fig. 3. Heat flux density versus time during quenching from $875^{\circ} \mathrm{C}$ spherical probe $38.1 \mathrm{~mm}$ diameter in low concentration of electrolyte at $20^{\circ} \mathrm{C}$.

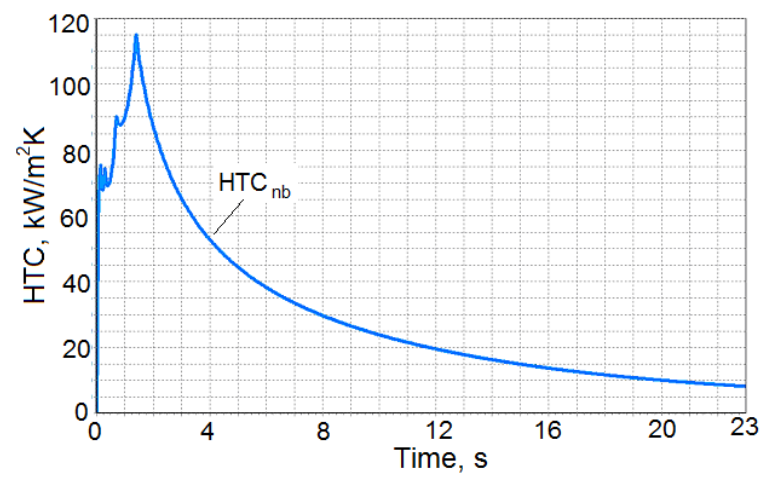

Fig. 4. Heat transfer coefficient evaluated as $\alpha=q /\left(T-T_{s}\right)$ versus time during quenching from $875^{\circ} \mathrm{C}$ the spherical probe $38.1 \mathrm{~mm}$ diameter in low concentration of electrolyte at $20^{\circ} \mathrm{C}$.

TABLE 1: THERMAL CONDUCTIVITY (W/MK)

\begin{tabular}{|c|c|c|c|c|c|c|c|c|c|c|c|}
\hline \multirow{2}{*}{ Material } & \multicolumn{10}{|c|}{$\mathrm{T},{ }^{\circ} \mathrm{C}$} & \multirow[b]{2}{*}{900} \\
\hline & 100 & 200 & \multicolumn{2}{|c|}{300} & \multicolumn{2}{|c|}{400} & 500 & 600 & 700 & 800 & \\
\hline AISI 304 & 15.6 & 17.6 & 19 & & 21 & & 22.3 & 23.6 & 24.8 & 25.2 & 27.0 \\
\hline Copper & 384.9 & 389.6 & 37 & & 36 & & 59.4 & 353.5 & 347.7 & 340.8 & 332.6 \\
\hline Silver & 392 & 372.2 & 361 & & 361 & & 66.3 & 374.5 & - & - & - \\
\hline \multicolumn{12}{|c|}{ TABLE 2: THERMAL DIFFUSIVITY OF COPPER IN $\mathrm{M}^{2} / \mathrm{S}$} \\
\hline \multirow{2}{*}{\multicolumn{2}{|c|}{ Material }} & \multicolumn{10}{|c|}{$\mathrm{T},{ }^{\circ} \mathrm{C}$} \\
\hline & & 100 & 200 & & 0 & 400 & 500 & 600 & 700 & 800 & 900 \\
\hline \multicolumn{2}{|c|}{$\begin{array}{l}\text { Steel } 304 \\
\times 10^{-6}\end{array}$} & 4.55 & 4.63 & & & 4.95 & 5.34 & 5.65 & 5.83 & 6.19 & 6.55 \\
\hline \multicolumn{2}{|l|}{$\begin{array}{c}\text { Copper } \\
\times 10^{-4} \\
\end{array}$} & 1.11 & 1.08 & & 94 & 1.01 & 0.98 & 0.94 & 0.91 & 0.89 & - \\
\hline
\end{tabular}


In contrast to obtained results of calculations, during quenching silver spherical probes in electrolytes, heat transfer coefficient increases versus time in $2-3$ times that contradicts the nucleate boiling theory. Solution was found by proposing phenomenon on forced heat exchange $[1,2]$. If the idea is true, the same increase of heat transfer coefficient must be observed during quenching of copper spherical probes in electrolytes. Some experimental data connected with the quench process of copper spherical probe is available from Fig. 1. Using obtained by French data and regular thermal condition theory of Kondrat'ev [6]-[8], it is possible to evaluate average heat transfer coefficients.

In Table 3 are provided core cooling rates of spherical copper samples depending on core temperature of the probe.

TABLE 3: COOLING RATE OF SPHERICAL COPPER SAMPLE 38.1 MM DIAMETER DURING QUENCHING IN ELECTROLYTE OF LOW CONCENTRATION AT $20^{\circ} \mathrm{C}$.

\begin{tabular}{cccc}
\hline T. ${ }^{\circ} \mathrm{C}$ & 700 & 500 & 350 \\
Cooling rate, ${ }^{\circ} \mathrm{C} / \mathrm{s}$ & 222 & 187 & 94 \\
\hline
\end{tabular}

Based on these data, extracted from Fig. 1, it is possible to evaluate HTCs using regular thermal condition theory. The method of evaluation is rather simple and is as following. Cooling rate, according to regular thermal condition theory is calculated by Eq. (2) [6], [7]:

$v=\frac{a K n}{K}\left(T-T_{s}\right)$

which can be rewritten as

$K n=\frac{v K}{a\left(T-T_{s}\right)}$

Here $K=\frac{R^{2}}{\pi^{2}}$. For spherical probe of thickness $38.1 \mathrm{~mm}$ diameter $K=36.77 \times 10^{-6} \mathrm{~m}^{2}$.

After evaluation of Kondrat'ev number $\mathrm{Kn}$, the generalized Biot number is evaluated from universal correlation (4):

$$
K n=\frac{B i_{V}}{\left(B i_{V}{ }^{2}+1.437 B i_{V}+1\right)^{0.5}}
$$

As known, the generalized Biot number $\mathrm{Bi}_{\mathrm{v}}$ is a value:

$$
B i_{V}=\frac{\alpha}{\lambda} K \frac{S}{V}
$$

Here $\alpha$ is heat transfer coefficient; $\lambda$ is thermal conductivity of metal; $\mathrm{S}$ is surface; $\mathrm{V}$ is volume.

Knowing its value, the specific heat transfer coefficient approximately is evaluated as:

$$
\alpha=\frac{\lambda B i_{V} V}{K S}
$$

Table 4 presents results of HTCs calculations versus core temperature of the copper spherical probe.
TABLE 4: HEAT TRANSFER COEFFICIENTS VERSUS CORE TEMPERATURE OF COPPER SPHERICAL PROBE 38.1 MM DIAMETER DURING QUENCHING IN

\begin{tabular}{ccc} 
ELECTROLYTE OF LOW CONCENTRATION AT & $20{ }^{\circ} \mathrm{C}$ \\
\hline $\mathrm{T},{ }^{\circ} \mathrm{C}($ Center$)$ & 700 & 500 \\
$\mathrm{~T},{ }^{\circ} \mathrm{C}($ Surface $)$ & 400 & 250 \\
$\mathrm{HTC}, \mathrm{W} / \mathrm{m}^{2} \mathrm{~K}$ & 30565 & 46630 \\
\hline
\end{tabular}

When surface temperature is $250{ }^{\circ} \mathrm{C}$ or $400{ }^{\circ} \mathrm{C}$, the developed film boiling takes place which is evaluated by Eq. (7) $[9]$ :

$\alpha_{F}=0.25\left(\frac{\lambda^{\prime \prime} c_{p}\left(\rho^{\prime}-\rho^{\prime \prime}\right)}{v^{\prime \prime}}\right)^{1 / 3}$

It is equal to $200 \mathrm{~W} / \mathrm{m}^{2} \mathrm{~K}$ that is 150 and 230 times lesser as compared with the results obtained in Table 4. Also, it can not be the nucleate boiling process because the surface temperature exceeds several times the critical value where film boiling starts. Only phenomenon on forced heat exchange can explain such differences.

\section{ANALYSIS OF PETRASH'S EXPERIMENTS}

The phenomenon of periodical replacement of film boiling by shock boiling explains such strange behavior of HTC presented in Table 4. If mentioned phenomenon is true, quenching in warm and hot electrolytes should decrease HTCs because film boiling prevails in this case. To check decreasing HTCs with increasing temperature of electrolyte, Petrash's experimental results of cooling rate measurements were used (see Fig. 5). Film boiling should prevail during quenching with increasing bath temperature because critical heat flux density decreases with decreasing underheat $\vartheta_{u h}$ (see Eq. (8)) [9], [10].

$$
q_{c r 1}^{u h}=q_{c r 1}\left[1+0.065\left(\frac{\rho^{\prime}}{\rho^{\prime \prime}}\right)^{0.8} \frac{c_{p} \vartheta_{u h}}{r^{\bullet}}\right]
$$

Here $\vartheta_{u h}=T_{s}-T_{m}$ is underheat in ${ }^{\circ} \mathrm{C}$.

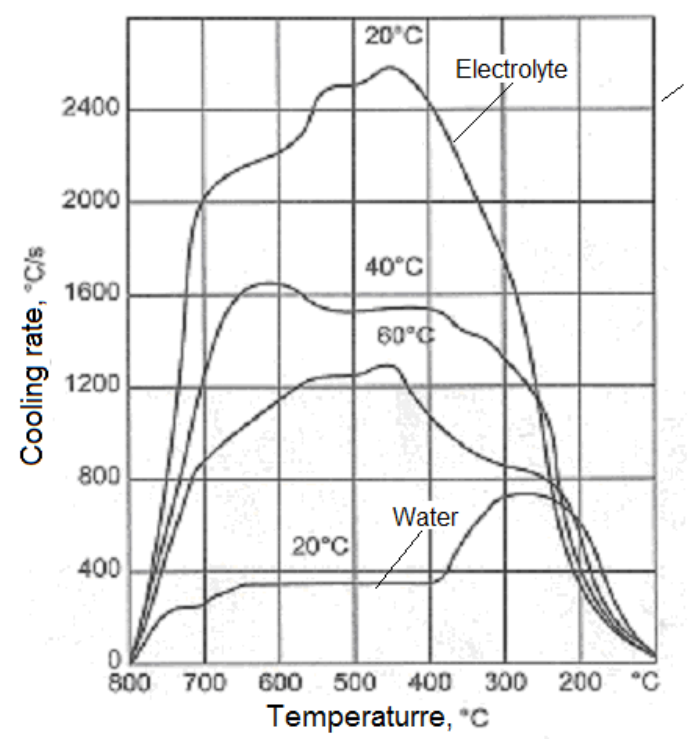

Fig. 5. Effect of temperature water $\mathrm{NaCl}$ solution (15\%) on cooling rate of silver spherical probe $20 \mathrm{~mm}$ diameter during quenching [4], [5]. 
The experimental results shown in Fig. 5 were used for calculating HTCs versus core temperature of silver spherical probe exploring the same method of calculation (see Eq. (6)). The results of calculations are provided in Table 5 and Table 6.

TABLE 5: EFFECT OF TEMPERATURE WATER NACL SOLUTION (15\%) AND CORE TEMPERATURE OF SILVER SPHERICAL PROBE 20 MM DiAMETER ON KONDRAT'EV NUMBER KN DURING QUENCHING IN ELECTROLYTES OF DIFFERENT TEMPERATURES

\begin{tabular}{|c|c|c|c|c|c|}
\hline \multicolumn{6}{|c|}{ DIFFERENT TEMPERATURES } \\
\hline $\begin{array}{l}\text { Temperature } \\
\text { of electrolyte }\end{array}$ & & & $\begin{array}{c}\mathrm{Kn} \\
(\mathrm{NaCl}) \\
\end{array}$ & & \\
\hline${ }^{\circ} \mathrm{C}$ & $700^{\circ} \mathrm{C}$ & $600^{\circ} \mathrm{C}$ & $500^{\circ} \mathrm{C}$ & $400^{\circ} \mathrm{C}$ & $300^{\circ} \mathrm{C}$ \\
\hline 20 & 0.208 & 0.270 & 0.385 & 0.489 & 0.532 \\
\hline 40 & 0.137 & 0.210 & 0.236 & 0.315 & 0.402 \\
\hline 60 & 0.0989 & 0.139 & 0.193 & 0.217 & 0.280 \\
\hline
\end{tabular}

TABLE 6: EFFECT OF TEMPERATURE WATER NACL SOLUTION (15\%) AND CORE TEMPERATURE OF SILVER SPHERICAL PROBE 20 MM DIAMETER ON HTC (W/M2K) DURING QUENCHING

\begin{tabular}{|c|c|c|c|c|c|}
\hline \multirow[t]{2}{*}{$\begin{array}{l}\text { Bath temperature, } \\
{ }^{\circ} \mathrm{C} \\
\end{array}$} & \multicolumn{5}{|c|}{$\begin{array}{l}\mathrm{HTC} \\
(\mathrm{NaCl}) \\
\end{array}$} \\
\hline & $700^{\circ} \mathrm{C}$ & $600^{\circ} \mathrm{C}$ & $500^{\circ} \mathrm{C}$ & $400^{\circ} \mathrm{C}$ & $300^{\circ} \mathrm{C}$ \\
\hline 20 & 27880 & 43670 & 69830 & 97880 & 116815 \\
\hline 40 & 18760 & 29615 & 34560 & 50030 & 71470 \\
\hline 60 & 13270 & 18880 & 27700 & 30970 & 42880 \\
\hline
\end{tabular}

Table 6 shows increasing HTCs vs decrease of core temperature of silver $20 \mathrm{~mm}$ probe. Simultaneously, with increasing bath temperature HTC decreases during quenching in electrolyte that is in good agreement with the idea on phenomenon discussed.

The effect of free electrons in metal on quenching process is considered in Refs [11]-[13]. Practical use of some innovations was discussed in publications [14]-[16]. The observed phenomenon can be further successfully investigated on the basis of solving hyperbolic heat conductivity equation with the boundary condition that takes into account electrical forces in the double electrical layer.

\section{DISCUSSION}

Obtained results of calculations and their analysis have shown that maximum heat flux density appears at the very beginning of quenching and it lasts within two initial seconds. Then the heat flux density quickly drops below the critical heat flux density that prevents the film boiling formation. Author [2] recommended using short time electrical external force to prevent process of film boiling formation at the initial time of quenching. Moreover, nowadays in heat treating industry water salt solutions of $\mathrm{NaNO}_{2}, \mathrm{NaNO}_{3}$ and $\mathrm{Na}_{2} \mathrm{CO}_{3}$ are used as a quenchant. As a rule, optimal concentration is used where dissolved cations and anions are at their maximum and the first critical density and HTC are maximal too (see Fig. 6). Note that the electrical conductivity of the water and water salt solutions depends on their temperature: the higher the temperature, the higher is the electrical conductivity. For example, the electrical conductivity of water increases by $2-3 \%$ for an increase of 1 degree Celsius of water temperature.

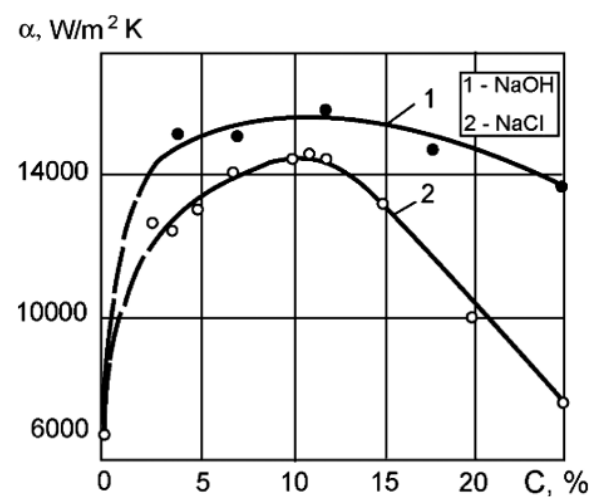

Fig. 6. Average heat transfer coefficients versus the concentration of $\mathrm{NaCl}$ and $\mathrm{NaOH}$ in water at 20_C [4].

According to the classical statistical thermodynamic, the pressure created by free electrons in metal is directly proportional to the absolute temperature $\mathrm{T}$ and is considered as:

$P=n k T$

where $\mathrm{n}$ is a number of electrons in one $\mathrm{sm}^{3}$ of metal; $\mathrm{k}$ is the Boltzmann constant which is equal to $k=1.3806488(13) \times 10^{-23}\left[J K^{-1}\right]$.

For the high electrical conductivity metals like silver and copper the number of free electrons $n_{m l}$ in one $\mathrm{sm}^{3}$ is several times larger as compared with steel, i.e., $n_{m l}>>n_{\text {steel }}$. As a result, in a double electrical layer high electrical forces appear when quenching such metals in electrolyte of optimal concentration (see Fig. 7).

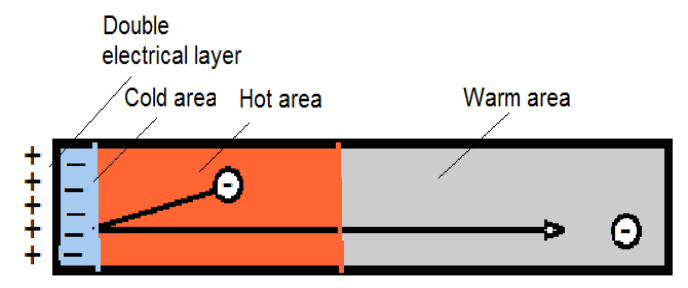

Fig. 7. Schematic explanation of creation the double electrical layer during quenching in electrolytes.

The experimental validation of existence electrical forces in the double boundary electrical layer that generates thermal waves (see Fig. 7) was made by authors [12] in 2017.

Due to free electrons in metal rather high electrical forces appear in double electrical boundary layer during quenching in electrolytes resulting in extremely high temperature gradients during immersion of metal into cold liquid. That is a reason for existence the replacement of film boiling by shock boiling. One should consider hyperbolic heat conductivity equation (5) with the boundary condition that takes into account electrical forces in the double electrical layer. It was established that during quenching probe (see Fig. 7) from $500{ }^{\circ} \mathrm{C}$ in water at $20{ }^{\circ} \mathrm{C}$, the left end of the probe does not generate visible thermal waves or impulses. Effect was observed when heated left end of the probe was immersed into electrolyte of optimal concentration [12]. It means that the double electrical layer is acting like 
amplifier bumping electrons from the left side to the right side (see Fig. 7). Several interesting effects were recorded which were discussed in [12].

The weak effect, concerning thermal wave distribution, follows from the solution of the hyperbolic heat conductivity equation. Authors [16], [17] considered hyperbolic heat conductivity Eq. (10) with the boundary and initial conditions (11) and initial condition (12)

$c \rho \frac{\partial T}{\partial \tau}+\tau_{r} \frac{\partial^{2} T}{\partial \tau^{2}}=\operatorname{div}(\lambda \operatorname{grad} T)+\frac{\partial q}{\partial T} \frac{\partial T}{\partial \tau}$

At present time the boundary condition (11) is used that doesn't take into account electrical forces in the boundary double electrical layer

$$
\left[\frac{\partial T}{\partial r}+\frac{\beta^{m}}{\lambda}\left(T-T_{S}\right)^{n}\right]_{r=R}=0
$$

Here $m=10 / 3$.

$$
T(r, 0)=T_{0}=\text { const }
$$

Authors [16, 17] came to conclusion that the analytical solving of formulated problem (10), (11), (12) is reduced to the problem of finding the unknown function from the following integral (13):

$$
h(\varphi)=g(\varphi) \cdot\left\{1-\int_{0}^{\varphi} G(\varphi, \psi) \cdot h(\psi) d \psi\right\}^{m}
$$

Here Green function $G(x, \xi, t)$ is classic Green function for heat conductivity equation with Neumann boundary conditions [16]:

$$
G(x, \xi, t) \stackrel{\text { def }}{\equiv} \frac{1}{l}+\frac{2}{l} \sum_{n=1}^{\infty} e^{-\left(\frac{a \pi n \sqrt{t}}{l}\right)^{2}} \cos \left(\frac{\pi n x}{l}\right) \cos \left(\frac{\pi n \xi}{l}\right)
$$

From the solving of the hyperbolic heat conductivity equation, authors [11] derived the thermal wave distribution:

$$
\theta_{\text {zero }}(x, \tau)=\frac{\sqrt{\tau_{r}} e^{-\frac{x^{2}}{4 a \tau}}}{\sqrt{\tau}}
$$

where $w_{r}=\sqrt{\frac{a}{\tau_{r}}}$ is the speed of thermal wave.

When $\tau=\tau_{r}$, Eq. (15) can be rewritten as [11]:

$\theta_{\text {zero }}(x, \tau)=e^{-\frac{x^{2}}{4 a \tau}}$

which resembles an instant impulse of the temperature known from the parabolic heat conductivity equation. Here $\mathrm{T}$ is a temperature; $\tau$ is a time; $\alpha$ is a heat transfer

coefficient $\left(\mathrm{W} / \mathrm{m}^{2} \mathrm{~K}\right) ; \lambda$ is a thermal conductivity of steel $(\mathrm{W} / \mathrm{mK}) ; \rho$ is a material density $\left(\mathrm{kg} / \mathrm{m}^{3}\right) ; q$ is a heat flux density $\left(\mathrm{W} / \mathrm{m}^{2}\right)$; c is a specific heat capacity; a is a thermal diffusivity of steel $\left(\mathrm{m}^{2} / \mathrm{s}\right) ; \mathrm{S}$ is a surface, $\mathrm{V}$ is a volume; $\mathrm{R}$ is a radius; $\mathrm{x}$ and $\mathrm{r}$ are coordinates; $\beta$ is equal to 3.41 for water.

As seen from Eq. (14), thermal signal is very weak because $r^{\bullet}$ is very small and exponent rapidly decreases versus time.

More information on solving of the hyperbolic heat conductivity equation suitable for conventional and intensive quenching processes is presented in Refs. [16], [17].

To successfully investigate behavior of forced exchange phenomenon and thermal wave distribution, the boundary condition should include electrical forces that take place during quenching metals in electrolytes. Currently, nobody is considered such approach which could bring many important solutions.

Further theoretical and experimental investigations should be done in this field. Especially important issue is the experimental validation the duration of external electrical force to be used at the beginning of metal quenching and its maximum value to eliminate completely any film boiling process during hardening of material. If carefully investigated, the heat treating industry will explore the most advanced technology with the many benefits being very cheap and simple as compared with existing technologies. The new technology can be controlled by patented in Ukraine system [18].

\section{CONCLUSION}

An idea on replacement the film boiling by shock boiling with the high frequency is supported by experimental data. The shock boiling generates forced heat transfer exchange (maximal HTCs) due to oscillating with the high frequency thousands of tiny vapor bubbles. Periodical resplendent of film boiling by shock boiling, that is the essence of discovered phenomenon, increases cardinally average heat transfer coefficient and HTC versus time. The innovation can be used for designing original quenching technology to save materials, increase service life of machine components, and improve environment condition. The phenomenon is observed during quenching in electrolytes of high thermal conductivity materials like silver, copper, and others.

\section{NOMENCLATURE}

$a$

$B i$

$B i_{V}$

$c_{p}$

$D$

Kn

$K$

$k_{F}$

$P$

$R$

$r^{\bullet}$
Thermal diffusivity of solid material in $\mathrm{m}^{2} / \mathrm{s}$ Conventional Biot number Dimensionless generalized Biot number Specific heat capacity in $\mathrm{J} / \mathrm{kg} \cdot{ }^{\circ} \mathrm{C}$

Diameter or thickness in $\mathrm{m}$ Kondrat'ev dimensionless number Kondrat'ev form factor in $\mathrm{m}^{2}$ Dimensionless form coefficient Pressure in $\mathrm{MPa}$ Radius in $\mathrm{m}$ Latent heat of vaporization in $\mathrm{J} / \mathrm{kg}$ 
$q_{c r 1} \quad$ The first critical heat flux density in $\mathrm{W} / \mathrm{m}^{2}$

$S \quad$ Surface in $\mathrm{m}^{2}$

$T \quad$ Temperature in ${ }^{\circ} \mathrm{C}$

$T_{o} \quad$ Initial austenitizing temperature in ${ }^{\circ} \mathrm{C}$

$T_{s} \quad$ Saturation temperature in ${ }^{\circ} \mathrm{C}$

$T_{m} \quad$ Bath temperature in ${ }^{\circ} \mathrm{C}$

$\alpha \quad$ Heat transfer coefficient in $\mathrm{W} / \mathrm{m}^{2} \mathrm{~K}$

$\beta \quad$ Function of physical properties of liquid

$\rho \quad$ Density in $\mathrm{kg} / \mathrm{m}^{3}$

$\rho^{\prime} \quad$ Liquid density in $\mathrm{kg} / \mathrm{m}^{3}$

$\rho^{\prime \prime} \quad$ Vapor density in $\mathrm{kg} / \mathrm{m}^{3}$

$v^{\prime \prime} \quad$ Kinematical viscosity of the vapor in $\mathrm{m}^{2} / \mathrm{s}$

$\lambda \quad$ Thermal conductivity in $\mathrm{W} / \mathrm{mK}$

$\tau_{r} \quad$ Relaxation time in $\mathrm{s}$

$\Omega \quad$ Function of convective $\mathrm{Bi}$ and temperature $\mathrm{T}_{\mathrm{o}}$

$\vartheta_{u h} \quad$ Underheat in ${ }^{\circ} \mathrm{C}$

\section{REFERENCES}

[1] N. I. Kobasko, "Unusual phenomenon of forced heat exchange taking place during quenching silver probe in cold electrolyte," Global Journal of Science Frontier Research - A: Physics and Space Science, Vol. 20, Issue 9, pp. 29 - 37, September 2020.

[2] N. I. Kobasko, "Phenomena of physics taking place during hardening steel in water salt solutions of optimal concentration," International Journal of Physics and Applications, Vol. 2, Issue 2, pp 6 -12, 2020.

[3] H. J. French, The Quenching of Steels, American Society for Steel Treating, Cleveland, OH, 1930.

[4] G.E. Totten, J. I. Dossett, N. I. Kobasko, "Quenching of Steel," ASM Handbook; Steel Heat Treating Fundamentals and Processes, Vol. 4A, 2013, pp. $91-157$.

[5] L. V. Petrash, "Some Physical Phenomena during Quenching," Metal Science and Heat Treatment, Vol. 15, No. 6, pp. 523 - 526, 1973.

[6] G. M. Kondrat'ev, Regulyarnyi Teplovoy Rezhim (Regular Thermal Mode), Gostekhizdat, Moscow, 1954, 364.

[7] G. M. Kondrat'ev, Teplovye Izmereniya (Thermal measurements), Mashgiz, Moscow, 1957, 250.

[8] A. V. Lykov, Teoriya Teploprovodnosti (Theory of Heat Conductivity), Vysshaya Shkola, Moscow, 1967, 596.

[9] V.I. Tolubinsky, Heat Transfer at Boiling. Naukova Dumka, Kyiv, $1980,316$.

[10] N.I. Kobasko, A. A. Moskalenko, G. E. Totten, and G. M. Webster, "Experimental Determination of the First and Second Critical Heat Flux Densities and Quench Process Characterization," Journal of Materials Engineering and Performance, Vol. 6, No. 1, 1997, pp. 93-101.

[11] N.I. Kobasko and Guseynov, Sh.E., "An Explanation of the Nature of Thermal Waves "a Poker Effect" on the Basis of Hyperbolic Heat Conductivity Equation Analysis and Existence of Free Electrons in Metals," Recent Researches in Circuits \& Systems, V.E. Balas, M. Koksal (Eds.), WSEAS Press, Athens, pp. 167 - 172, 2012, ISSN: $1790-5117$.

[12] N.I. Kobasko and Moskalenko A.A., "Physics of "Poker effect", International Journal of Current Research, '2018, 10, (12), 7639976405.

[13] N.I. Kobasko, "Thermal Waves, Thermal Diffusivity and Possibility of Relaxation Time of Materials Evaluation," SSRG International Journal of Applied Physics (SSRG-IJAP). 2019; 6(3):66-73.

[14] N.I. Kobasko, Aronov M. A., Powell J. A., Totten G. E., "Intensive Quenching Systems: Engineering and Design". ASTM International, USA, 2010. 234 p. doi: 10.1520/mnl64-eb.

[15] Sh. E. Guseynov, A. Buikis, N.I. Kobasko, "Mathematical statement of a problem with the hyperbolic heat conductivity equation for the intensive quenching processes," Proc. of the Seventh International Conference "Equipment and Technologies for Heat Treatment Metals and Alloys (OTTOM-7), Kharkov, Ukraine, Vol. 2, pp. 22 27, 2006.

[16] Sh. E. Guseynov, J. S. Rimshans, N.I. Kobasko, "On one non - linear mathematical model for intensive steel quenching and its analytical solution in closed form," Progress in Industrial Mathematics at ECMI (Mathematics in Industry 15), Fitt AD, et al. (Eds.). Springer Verlag, Berlin, Heidelberg, 2010, 857-862.
[17] Andris Buikis, Multidimensional Mathematical Models for Intensive Steel Quenching, Lambert Academic Publishing, Germany, 2020, 128.

[18] Ukrainian patent UA No. 119230, Filed on Sept. 4, 2015. 